\title{
FOOD SECURITY CONDITION OF LANDLESS PEOPLE IN A CHAR AREA OF RANGPUR DISTRICT
}

\author{
M. Shahiduzzaman', M. Z. Rahman'², M. J. Hoque ${ }^{3}$ and M. S. Arefin ${ }^{4}$ \\ Department of Agricultural Extension Education, Bangladesh Agricultural University \\ Mymensingh-2202, Bangladesh
}

\begin{abstract}
The study was conducted to investigate the food security condition of households of landless char people at Purba Isli village of Lakshmitary union, Gangachara Upazila of Rangpur District. Data were collected from a random sample of 80 where the total landless char people were 400 . A structured interview schedule was used for collecting data during April to May 2012. Food security condition of households of landless char people was measured on the basis of their per capita calorie consumption per day. Coefficient of correlation ( $r$ ) was computed to explore relationship of the respondents' selected characteristics and their food security condition. More than half (57.5 per cent) of the households were food secure and energy intake was $2122 \mathrm{kcal} /$ person/day. On the other hand, 21.3 per cent household were food insecure and consumed between 1805 and $2121 \mathrm{kcal} /$ person/ day and 21.3 per cent households were found severely food insecure and calorie intake was less than $1805 \mathrm{kcal} /$ person/day. Thus, it can be concluded that nearly half of the landless char people were food insecure. Landless char people's year of schooling, landlessness category, annual household income, training experience, and credit received, extension media contact, involvement in NGO, perceived strategies to cope with food insecurity and perception of organizational food insecurity mitigation initiatives had significant positive relationship with their household food security condition.
\end{abstract}

Key Words: Food security, Landless people, Char area

\section{INTRODUCTION}

Bangladesh remains highly food insecure in spite of important economic progress. Bangladesh is ranked 129th out of 169 countries in the 2010 Human Development Index (HDI) (UNDP, 2010). About 60 million people consume less than the minimum daily recommended amount of food (HIES, 2005). According to IFPRI's 2009 Global Hunger Index-which is a combined measure of the proportion of undernourishment, child malnutrition and child mortality- food security has improved in Bangladesh since 1990, with country moving from an "extremely alarming" to an "alarming" level of hunger. The proportion of undernourished has fallen from 36 per cent of the population to 26 per cent in

${ }^{1} \&^{4}$ Former M.S. Student, 2 Professor, ${ }^{3}$ Associate Professor, Department of Agricultural Extension Education, Bangladesh, Agricultural University, Mymensingh-2202, Bangladesh

*Correspondence author (Email: zulfikar64@yahoo.com) 
2006. Despite this progress, Bangladesh's food security is still fragile and major challenges remain as well.

The revering sand and still landmasses known as char in Bengali are home to over 6 million people in Bangladesh. The char dwellers mainly depend on agriculture and agriculture related activities. Opportunities for off-farm activities are marginal. As a result of river erosion, cultivable land, crops and homestead are often damaged or devoured by rivers regularly. The level of awareness with respect to health, water and sanitation, environment, rights and gender is at a minimum. The life of char people in Bangladesh is very much uncertain and vulnerable to so many shocks of the environmental factors. But the need to secure food is a certain matter to continue their lives. Special emphasis also is to be placed on the landless people of char areas as they do not have their own land to produce enough food to meet household food demand.

Development of char livelihood, knowing of position of food security of char people is essential where a major portion is secured by a landless people. If their state of food insecurity is revealed, careful and need-based interventions may possibly be taken properly to mitigate the crises. For this reason, it was deemed necessary to undertake this study with the following objectives: i) to explore the condition of household food security of landless char people; ii) to find out the relationship between the characteristics of landless char people and their household food security; and iii) to find out the reasons of food insecurity of landless char people.

\section{METHODOLOGY}

The study was conducted in Purba Isli village under Gangachara Upazila of Rangpur district. An updated list of landless char people of the selected village was prepared by the help of the Rangpur Dinajpur Rural Service (RDRS), Debi Chowdhurani Palli Unnayon Kendra (DCPUK) and Union Parishad. In total, there were 400 landless people (head from each household) in this char village which were considered as the population of the study. Twenty per cent of the population was randomly selected by using a Table of Random Numbers. Thus, a total of 80 char people constituted the sample size for the study.

Personal interview method was used for data collection from the household heads of the village using structured interview schedule. The interview was conducted mainly for assessing characteristics of the landless char people and their condition of food security at household level. FGD (Focus Group Discussion) was also conducted to select the different aspects of perceived strategies to cope with food security condition. Additionally, FGD was conducted to reveal the reasons of food insecurity of the respondents' households.

The focus variable of the study was "Food security condition of the household of landless char people". The selected characteristics of the landless char people were their age, years of schooling, landlessness category, annual household income, training experience, credit received, extension media contact, involvement in NGO, strategies to cope with food insecurity and perception of organizational food insecurity mitigation initiatives. 
The household food security condition of selected landless char people was determined using the consumption approach. Consumption is preferable to measure food security than income because it is less vulnerable to seasonality and life-cycle, less vulnerable to measurement errors because respondents have less reasons to lie, it is closer to the utility that people effectively extract from income, and for the poor most of income is consumed (FAO, 2002). To obtain the actual calorie consumption by the household members, Household Calorie Acquisition method was used. First, the gross household food consumption of last 7 days was converted into calories. Due to differences in household compositions in terms of age and sex, there was a need to adjust the household size to adult equivalent household size. Adult equivalence was developed by World Health Organization considering the nutritional requirements of an individual by age and gender. Adult equivalence table is used as a reference to calculate adult equivalent household size in this study. Finally, a concise figure for average calories consumed per person per day was calculated and compared with an estimate of threshold kilocalorie level requirement i.e. $2122 \mathrm{kcal}$ (HIES, 2010). The similar methodology was used by Mahzabin (2011) in her study to investigate the food security status of farmers at plain land.

Various statistical measures such as range, mean, number percentage, standard deviations etc. were used to describe the selected characteristics of the respondents of the study area. In order to find out the relationship between the individual characteristics of the landless char people and their food security condition, Pearson's Product Moment correlation coefficient ( $r$ ) was computed.

\section{RESULTS AND DISCUSSION}

\section{Salient traits of landless char people}

Age of the respondents ranged from 23 to70 years with an average of 41.24 years and a standard deviation of 11.41 years (Table 1 ). Majority (47.5 per cent) of the landless char people were in the middle aged and 42.5 per cent belonging to young aged category and 10 per cent to old aged category. The year of schooling of the landless char people ranged from 0 to 10 and the average was 1.46 with a standard deviation of 2.49. Among the total respondents 72.5 per cent could not read or write, 12.5 per cent had primary and 15 per cent had secondary level of education. Landlessness category of the landless char people ranged from 0 to 0.42 and the average was 1.36 with a standard deviation of 0.56 . Majority of the respondents (67.5 per cent) were in the category landless- $1,28.8$ per cent landless- 2 and rest 3.8 per cent in the category- 3 .

Annual household income of the landless char people ranged from 10 to 72 thousand in Taka. The average income was 31.96 thousand Taka and standard deviation of 12.67. The findings revealed that equal per cent of the respondents (50 per cent) had low and medium annual household income but none had high annual income. Majority (60 per cent) of the landless char people had no training experience, while 40 per cent had training experience. Credit received score of the respondents ranged from Taka 0 to 20 thousand with a mean of 2.94 and standard deviation of 3.91 (Table 1). More than half (55 per cent) of the respondents 
were in the small category, 33.75 per cent not at all, 8.8 per cent medium, rest 2.5 per cent were in high category.

Table 1. Salient features of the landless char people

\begin{tabular}{|c|c|c|c|c|c|c|c|c|}
\hline \multirow[t]{2}{*}{ Characteristics } & \multirow{2}{*}{$\begin{array}{l}\text { Measuring } \\
\text { unit }\end{array}$} & \multicolumn{2}{|c|}{ Range of score } & \multicolumn{3}{|c|}{ Respondents } & \multirow[t]{2}{*}{ Mean } & \multirow[t]{2}{*}{ SD } \\
\hline & & Possible & Observed & Categories & Number & Per cent & & \\
\hline \multirow[t]{3}{*}{ Age } & Year & Unknown & $23-70$ & Young $(\leq 35)$ & 34 & 42.5 & 41.24 & 11.41 \\
\hline & & & & Middle-aged (36-55) & 38 & 47.5 & & \\
\hline & & & & Old $(>55)$ & 8 & 10.0 & & \\
\hline \multirow{4}{*}{$\begin{array}{l}\text { Year of } \\
\text { schooling }\end{array}$} & Year & Unknown & $0-10$ & Cannot read or write $(0)$ & 58 & 72.5 & 1.46 & 2.49 \\
\hline & & & & Primary (1-5) & 10 & 12.5 & & \\
\hline & & & & Secondary (6-10) & 12 & 15.0 & & \\
\hline & & & & HSC (11-12) & 0 & 0 & & \\
\hline \multirow{4}{*}{$\begin{array}{l}\text { Landlessness } \\
\text { category }\end{array}$} & Category & $0-\leq 0.42$ & $0-0.2$ & Landless 1 (no household) & 54 & 67.4 & - & - \\
\hline & & & & Landless 2 (household) & 23 & 28.8 & & \\
\hline & & & & Landless 3 ( $\leq 0.2 \mathrm{ha})$ & 3 & 3.8 & & \\
\hline & & & & Landless 4 (>0.21- $\leq 0.42$ ha) & 0 & 0 & & \\
\hline \multirow{9}{*}{$\begin{array}{l}\text { Annual } \\
\text { household } \\
\text { income } \\
\text { Training } \\
\text { experience } \\
\text { Credit received }\end{array}$} & ‘000’Taka & - & $10-72$ & Low $(\leq 48)$ & 40 & 50 & 31.96 & 12.67 \\
\hline & & & & Medium (49-72) & 40 & 50 & & \\
\hline & & & & High $(>72)$ & 0 & 0 & & \\
\hline & No. & - & $0-10$ & No Training & 48 & 60 & - & - \\
\hline & & & & Training received & 32 & 40 & & \\
\hline & Score & - & $0-20$ & Not at all $(0)$ & 27 & 33.7 & 2.94 & 3.91 \\
\hline & & & & Small $(\leq 7)$ & 44 & 55.0 & & \\
\hline & & & & Medium (8-14) & 14 & 17.5 & & \\
\hline & & & & High $(>14)$ & 2 & 8.8 & & \\
\hline \multirow{3}{*}{$\begin{array}{l}\text { Extension } \\
\text { media contact }\end{array}$} & Score & $0-21$ & $0-20$ & Low $(\leq 7)$ & 22 & 27.5 & 4.20 & 4.38 \\
\hline & & & & Medium (8-14) & 58 & 72.5 & & \\
\hline & & & & $\operatorname{High}(>14)$ & 0 & 0 & & \\
\hline \multirow{3}{*}{$\begin{array}{l}\text { Involvement in } \\
\mathrm{NGO}\end{array}$} & Score & - & $0-5$ & Not at all $(0)$ & 47 & 58.7 & 0.66 & 0.97 \\
\hline & & & & Short term (1-3) & 32 & 40.0 & & \\
\hline & & & & Long term $(>3)$ & 1 & 1.3 & & \\
\hline \multirow{3}{*}{$\begin{array}{l}\text { Perceived } \\
\text { strategies to } \\
\text { cope with food } \\
\text { insecurity }\end{array}$} & Score & $0-48$ & $3-22$ & Low (0-16) & 1 & 1.3 & 7.82 & 4.72 \\
\hline & & & & Medium (17-32) & 70 & 87.4 & & \\
\hline & & & & High (33-48) & 9 & 11.3 & & \\
\hline $\begin{array}{l}\text { Perception of } \\
\text { organizational }\end{array}$ & Score & $0-16$ & $3-15$ & $\begin{array}{c}\text { Unfavourable }(\leq 7) \\
\text { Moderately favourable }\end{array}$ & 15 & 18.8 & 10.11 & 3.10 \\
\hline food insecurity & & & & $(8-14)$ & 59 & 73.7 & & \\
\hline $\begin{array}{l}\text { mitigation } \\
\text { initiatives }\end{array}$ & & & & Favourable (>14) & 6 & 7.5 & & \\
\hline
\end{tabular}

The extension media contact score of the landless char people ranged from 0 to 13 . The mean and standard deviation were 4.2 and 4.38 respectively. Majority of the respondents had (72.5 per cent) medium extension media contact, while rest 27.5 per cent had low contact. Involvement in NGO by the landless char people ranged from 0 to 5 years. More than half of the respondents (58.8 per cent) weren't involved in any NGO, while 40 per cent were short term and rest 1.3 per cent were involved in different NGOs with a mean of 0.66 and standard deviation of 0.97 .

Strategies to cope with food insecurity score of the respondents ranged from 3 to 22 with a mean and standard deviation of 7.82 and 4.72 respectively. The highest proportion (87.5 per 
cent) of the respondents had medium level of coping strategy, while 11.3 per cent had high and 1.2 of them had high level strategies to cope with food insecurity.

The perception of organizational food insecurity mitigation initiatives score of the respondents ranged from 3 to 21. The mean and standard deviation were 10.11 and 3.10 respectively. Majority (73.8 per cent) of the respondent were moderately favorable perception of organizational food insecurity mitigation initiatives, while 7.5 per cent had favorable perception and 18.8 per cent were unfavorable perception.

\section{Food security condition of the landless char people}

The calorie consumption per person per day in a household ranged from 1106.68 to 3960.74 $\mathrm{kcal}$. The average daily per capita calorie intake by households was estimated to be 2250.44 $\mathrm{kcal}$ with a standard deviation of 576.82. The average was lower than the national average of $2318.3 \mathrm{kcal}$ (HIES, 2010). Based on the food security condition, landless char people have been classified into three categories as highly insecure, moderately food insecure and food secure. The household food security condition of the respondents has been shown in Table 2.

Table 2. Household food security condition of the respondents

\begin{tabular}{|c|c|c|c|c|}
\hline \multirow[t]{2}{*}{ Categories of food security } & \multicolumn{2}{|c|}{ Respondents } & \multirow[t]{2}{*}{ Mean } & \multirow[t]{2}{*}{ SD } \\
\hline & Number & Per cent & & \\
\hline Food secure ( $\geq 2122 \mathrm{kcal} /$ day/person) & 46 & 57.4 & 2250.44 & 576.82 \\
\hline Moderately food insecure (1805-2121 kcal/day/person) & 17 & 21.3 & & \\
\hline Highly insecure (<1805kcal/day/person) & 17 & 21.3 & & \\
\hline Total & 80 & 100.00 & & \\
\hline
\end{tabular}

The minimum calorie requirement set in Bangladesh is $2122 \mathrm{kcal} /$ person/day (HIES, 2010). The table revealed that more than half (57.4 per cent) of the households were found food secure and had a calorie intake of 2122 or more $\mathrm{kcal} /$ person/day and 21.3 per cent households consumed between 1805 and $2121 \mathrm{kcal} /$ person/day and these households were food insecure. However, 21.3 per cent households were severe food insecure as people from these households consumed less than $1805 \mathrm{kcal} /$ person/day. Findings show that food insecurity still lingers as a truth for the landless char people. Their access to food is hindered due to lack of purchasing capacity and quite a few other factors including damages by river erosion and natural calamities and seasonal market fluctuation of commodities.

About fifty per cent of the landless households yet remain in a state of moderate and highly food insecure conditions. It is assumed that the real situation of food insecurity is much graver in the sense that food security in this study has been measured considering the calorie intake of the households. This method may give a slight deviation of nutritional security as the main calories were met by carbohydrate intake in the households. Nonetheless, a matter of little contentment regarding food security remain for landless char 
inhabitants due to some off-farm income generating initiatives of different government and non-government organizations.

\section{Relationship between selected characteristics of the landless char People and their food security condition}

Findings indicated that age of the char people was not an important indicator concerning the food security condition, but the year of schooling and household food security condition were significantly and positively correlated (Table 3). That is, the educated char people are more food secure. Landlessness category in the respondent had significant relationship with their food security condition. That is, the increase of the land of the respondent, the more they were food secure. Annual household income of the respondent had significant positive relationship with their food security condition. It can be concluded that higher the income, the higher was the probability that the household would be food secure. Training experience of the respondent had significant positive relationship with their food security condition. That is, the more the training experience of the respondents, the more they were food secure. Extension media contact had significant positive relationship with their food security condition. It indicates that extension media contact had been linked to food security condition. Involvement in NGOs had also significant positive relationship with their food security condition. The main reason of this result might be that NGOs placed a great importance locally on their food security condition. Perceived strategies to cope with food security had positive and significant relationship with their food security condition. Thus, it might be said that who perceived more strategies at a time, he was more food secure. Perception of organizational food insecurity mitigation initiatives of the landless char people had significant relationship with their household food security condition. It might be said that more favorable perception help ensure food security.

Table 3. Correlation co-efficient between selected characteristics of the landless char people and their food security condition

\begin{tabular}{l|l|c}
\hline \multicolumn{1}{c|}{ Dependent variable } & \multicolumn{1}{c}{ Independent variables } & $\begin{array}{c}\text { Computed ' } \mathrm{r}^{\prime} \text { values } \\
\text { with 78 df }(\mathrm{n}=80)\end{array}$ \\
\hline $\begin{array}{l}\text { Food security condition } \\
\text { (Calorie intake per day per } \\
\text { person) }\end{array}$ & Age & -0.075 \\
& Year of schooling & $0.307^{* *}$ \\
& Landlessness category & $0.265^{*}$ \\
& Annual household income & $0.401^{* *}$ \\
& Training experience & $0.580^{* *}$ \\
& Credit received & -0.093 \\
& Extension media contact & $0.379^{* *}$ \\
& Involvement in NGOs & $0.555^{* *}$ \\
& Strategies to cope with food insecurity & $0.278^{*}$ \\
& Perception of organizational food & $0.317^{* *}$ \\
\hline
\end{tabular}

* Significant at 5 per cent level of probability; ** Significant at 1 per cent level of probability 


\section{Suggestions to ensure food security}

At the time of interview the landless char people were asked to indicate the probable suggestions to ensure food security. The suggestions provided by them are summarized as follows:

1. Majority of the landless char people of the study area were dependent on agricultural labor as their main source of income. At the lean period, landless char people usually remain idle and do not have the opportunity to earn enough money to satisfy their food and other basic needs. It was suggested that creation of alternative income generation may help them earn more to meet the food cost of the household.

2. River erosion and flood make an extensive damage to the land and crop in the study area regularly. It was suggested for construction of a dam to prevent the losses.

3. Construction of a bridge over Tista river for better communication.

4. Aids from GOs and NGOs for their development of household food security.

5. Introduction of social and institutional safety net programs to overcome the seasonal shortage of food and temporary income generation.

6. Off-farm income generation for landless people in lean period through small credit programs of NGOs.

7. Capacity of landless farmers is to be strengthened to have secured access to market interventions.

\section{Reasons for household of food insecurity for of landless char people}

The causes of household food insecurity are evident from the above discussion of the various dimensions of the concept of food security and the findings of the study. The ability of a household to command adequate food resources - through self-production or market transactions - is primarily dependent upon assets and/or income. In agrarian societies, land ownership has been shown to be a sensitive indicator of wealth, and studies have indicated that under nutrition is associated with the lack of such a productive asset and/or low effective income. There are studies, however, that have shown that landless people are not likely to be at greater risk of chronic under nutrition in semi-arid areas, where land and water conditions are relatively poor. It is also evident in studies that seasonal variations in work and food - major sources of acute under nutrition - are actually worse for farmers than equally poor landless laborers. Land, however, can be mortgaged, and thus, offers some protection against nutritional deprivation.

The reasons for the household food insecurity of landless char dwellers have been revealed through focus group discussion (FGD) which are recorded below in Table 4.

The degree of access to markets is of obvious importance even for the landless farmers. There must have ease in collecting agricultural inputs and sale of outputs. Moreover, care is needed by the extension and other departments of the government to train the landless agricultural wage laborers to become workforce of off-farm income generation. Only toiling 
over land may not generate adequate income to secure minimum food for the family and buy their daily necessities.

Table 4. Reasons of household food insecurity as mentioned by farmers

\begin{tabular}{|c|c|}
\hline Reason for household food insecurity & Rank order \\
\hline $\begin{array}{l}\text { Inadequate control and quality of assets including small area of land if they would } \\
\text { have any }\end{array}$ & 1 \\
\hline Inadequate wages, underemployment and unemployment in lean season & 2 \\
\hline High food prices compared to wages & 3 \\
\hline Inadequate physical and economic access to markets and other factors & 4 \\
\hline $\begin{array}{l}\text { Inadequate government and non-government interventions for off-farm income } \\
\text { generation of landless people in chars }\end{array}$ & 5 \\
\hline Less contact to extension personnel and media & 6 \\
\hline $\begin{array}{l}\text { Dependence on markets which do not operate perfectly and may interlock to } \\
\text { further impoverish households }\end{array}$ & 7 \\
\hline $\begin{array}{l}\text { Seasonality in food availability, labor demand, hence food prices and incomes } \\
\text { may result in transitory food insecurity and cause fluctuations in individual } \\
\text { nutritional status }\end{array}$ & 8 \\
\hline $\begin{array}{l}\text { Tenants are sometimes being forced to pay rents in kind after harvest when prices } \\
\text { are low }\end{array}$ & 9 \\
\hline
\end{tabular}

\section{CONCLUSIONS}

Forty four per cent of the landless households remain under either moderate or severe food insecurity category which indicates a grave scenario in char area. Landless char dwellers' suggestions to ensure better food for the households were mainly centered on alternate income generation through technical supports from NGOs and concerned departments of GOs. It may, thus, be indicative that the landless people entirely did like to get financial grants aids to improve their household food security condition.

Positive significant relationships of years of schooling and extension media contact with information sources of the landless char people with their household food security status point toward the idea that education might help change attitude of the household head. This, in turn, it might enable them to adopt new techniques of income generation. Consequently, it might have help achieve household food security. Moreover, it is indicative that household income augmentation might play a key role in securing household food security. Inadequate control and quality of assets, less wages for laborers, unemployment in lean season, food price fluctuation are some of the major hindrances to secure food in landless char peoples. All the issues are related to more or less local and government policy issues which exert effects on food security condition. Due care is needed to address these problem issues in order to secure food for the char inhabitants in the study area. Local government with the help of local NGOs might exert their efforts towards proper direction in this matter. 


\section{REFERENCES}

Anonymous. 2006. National Food Policy 2006. Ministry of Food and Disaster Management. Government of the People Republic's of Bangladesh, Dhaka.

BBS. 2010. Statistical pocket book of Bangladesh. Bangladesh Bureau of Statistics, Ministry of Planning, Government of the People's Republic of Bangladesh, Dhaka.

FAO. 2002. The state of food insecurity. Food and Agricultural Organization of the United Nations, Rome.

HIES. 2010. Household income and expenditure survey. Bangladesh Bureau of Statistics, Government of the People's Republic of Bangladesh, Dhaka.

HIES. 2005. Household income and expenditure survey. Bangladesh Bureau of Statistics, Government of the People's Republic of Bangladesh, Dhaka.

HKI. 2003. Life in the chars in Bangladesh: nutritional surveillance project bulletin no. 14. Retrieved from http://Pdf.usaid.gov/pdf_docs/PNACT 449.pdf (19 March 2012).

IFPRI. 2009. Bangladesh food security investment forum, May 26, 2010- May 27, 2010.Retrieved from: http:/ / www.ifpri.org/event/ bangladesh-food-security-investment-forum (21 March 2012).

Mahzabin, I. A. 2011. Household food security status of selected farmers in Phulpur upazila of Mymensingh district, M.S Thesis. Department of Agricultural Extension Education, Bangladesh Agricultural University, Mymensingh.

UNDP. 2010. Human development index. United Nations Development Programme. New York. Retrieved from: http://hdr.undp.org/en/media/PR3-HDR10-HD1-E-rev4.pdf (20 March 2012). 